\title{
MECHANISM OF RIGID OVERLAYING OF CARBONIFEROUS STRATA FAILURE IN FACE MINING IN THE CASE OF A MULTISEAMS DEPOSIT
}

\author{
Eva JIRÁNKOVÁ ${ }^{1) *}$, Lubomír STAŠ ${ }^{2)}$, Vlastimil KAJZAR ${ }^{2)}$ and Hana DOLEŽALOVÁ ${ }^{2)}$ \\ 1) Vঙ̌B-Technical University of Ostrava, 17. Listopadu 15/2172, 70833 Ostrava-Poruba, Czech Republic \\ 2) Institute of Geonics of the AS CR, v.v.i., Studentska 1768, 70800 Ostrava-Poruba, Czech Republic \\ *Corresponding author's e-mail: eva.jirankova@vsb.cz
}

(Received July 2012, accepted October 2012)

\begin{abstract}
The technique of assessing the failure of rigid overlying strata is applicable to deep mining with thick coal seams (a thickness of more than $1 \mathrm{~m}$ in the Ostrava-Karvina Coalfield), and in one case to longwall mining with controlled caving. The assessment of failure of rigid overlying strata makes it possible to distinguish whether the rigid overlying strata of rocks has been deformed or whether a strutting arch has been formed over the goaf below which is an area that is free from stress. Good knowledge of the mining, technical and geological conditions of a given site is a prerequisite for successful evaluation.

There are advantages to utilising surface measurements for interpreting the effects of changes in rock mass, especially in areas of high overlying strata. The practical importance of failure assessment of overlying strata consists in determining the size of the mined-out area where the deformation of the rigid overlying strata occurred, which is dependent on the character of the rock mass.

This paper is set in the context of the expected width of the goaf during deformation of rigid overlying strata within parameters that describe the mining and geological conditions of the locality. Changes in the area of the goaf, based the results of tensometric measurements, will also be placed in context.
\end{abstract}

KEYWORDS: subsidence trough, rock mass, overlying strata, longwall mining, tensor stress measurement

\section{INTRODUCTION}

The results of surface subsidence measurements can be used for assessing the failure of the strata overlying the exploited seams. In many cases, a strutting arch is created over the mined out space, and there is no force strong enough to cause failure of the entire thickness of the relatively consistent and rigid overlying strata. When the strutting arch is created, a very large and concentrated rock load can occur, and anomalous geomechanical events may arise. However, even in cases where the intact overlying strata are breaking, the range of the breaking must be precented from extending due to subsequent exploitation. Overhangs of the unfaulted firm layers which are tailed into the non-undermined overlying strata take a part in a considerable surcharge of the affected area. That is why in this area a high stress concentration occurs.

\section{LOCALITY DESCRIPTION}

This article presents the results of an assessment of the failure of overlying strata from the mining panel 340206 at the $40^{\text {th }}$ seam in the second block of the Darkov mining area. Mining operations started in July 2011. The extraction is being performed by advanced longwall mining with controlled caving, with an average extracted thickness of $5 \mathrm{~m}$. The advancement of the longwall face and previous mining in the area surrounding the assessed mining panel is presented in Figure 1. The average daily progress of the mining is approximately $3 \mathrm{~m}$. The exploited section of the $40^{\text {th }}$ seam in the second block of the Darkov mining area is located at a depth of $800 \mathrm{~m}$. Previous mining of the $39^{\text {th }}$ seam was undertaken at a depth of $770 \mathrm{~m}$. These seams form part of the Saddle members of the Karviná formation. The general dip of layers in the second block is 5 to $10^{\circ}$ to the NNE.

Information about the conditions of the overlying strata was obtained from borehole M4-61. This contains a $26 \mathrm{~m}$ thick interlayer between coal seams 39 and 40. The interlayer is mostly comprised of coarse-grained sandstones and conglomerates. The rigidity of the effective overlying strata of the $40^{\text {th }}$ seam is characterized by an inflexibility coefficient value of 10.9. The effective overlying strata of the $40^{\text {th }}$ seam is approximately $30 \mathrm{~m}$ thick (six times the extracted thickness). The interlayer between coal seams $37 \mathrm{f}$ and 39 is $44 \mathrm{~m}$ thick and it consists mainly of coarse and fine-grained sandstone.

The tectonic evolution of the area is very complicated. West of mining panel 340206 there is found the tectonic fault Gabriela, inclined $70^{\circ}$ to the 


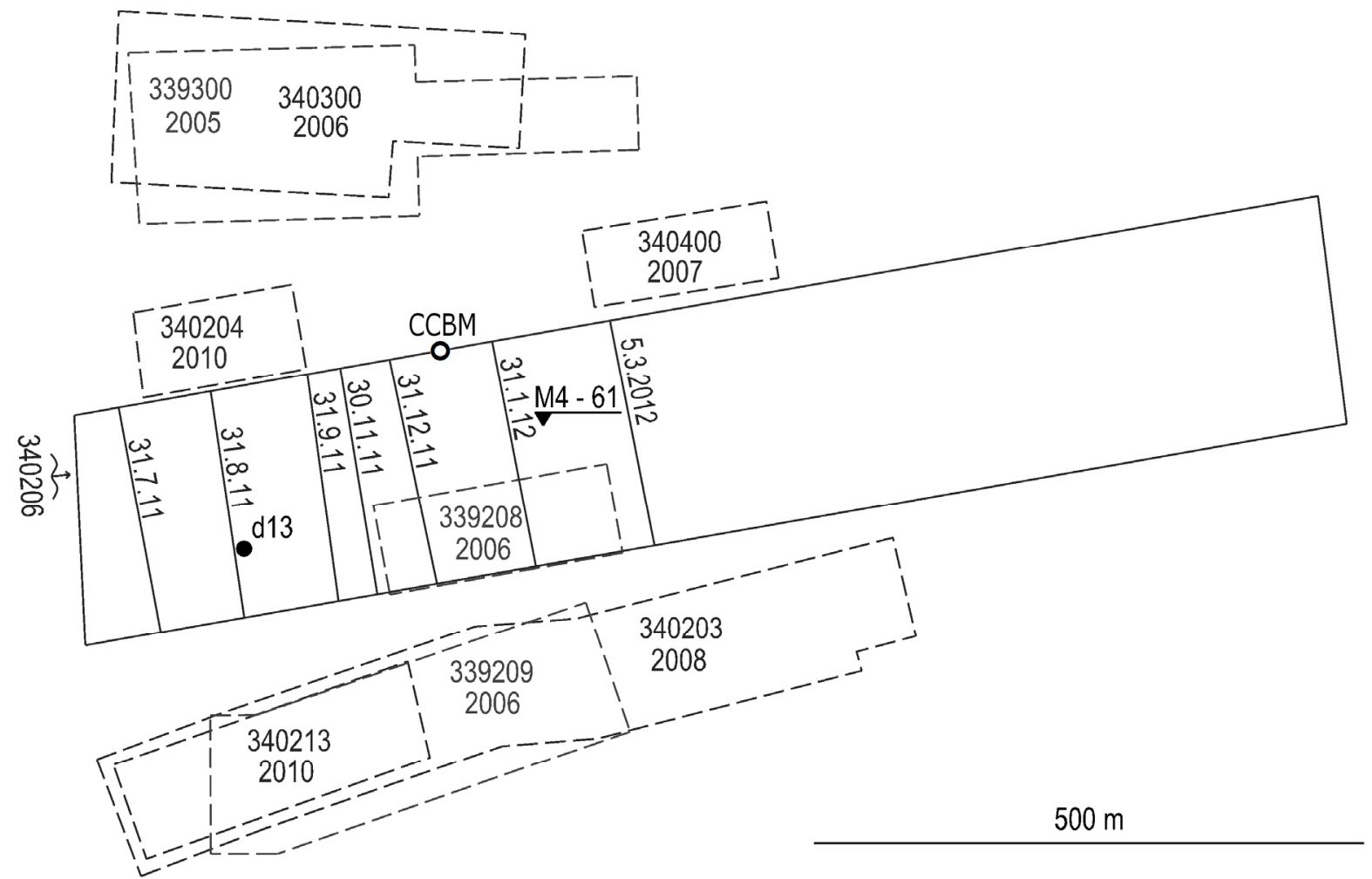

Fig. 1 Position of borehole M4-61 and surface point d13 in relation to mining panel 340206 and previous mining.

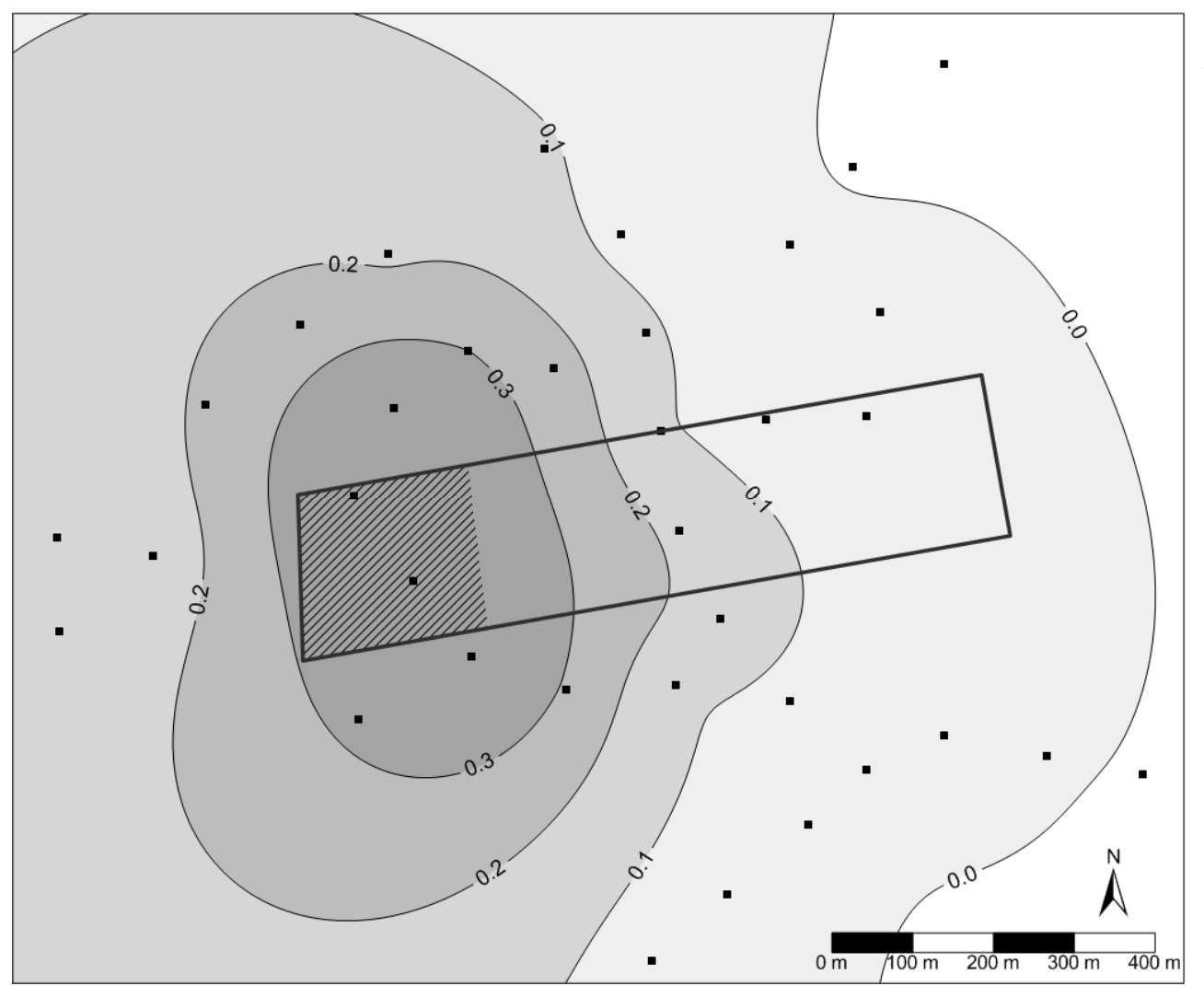

$2011 / 07-2011 / 10$

Subsidence $(\mathrm{m})$

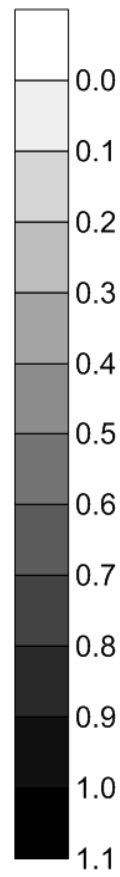

Fig. 2 Contour map of surface subsidence and mined out area of the 340206 mining panel before October $13^{\text {th }} 2011$. 


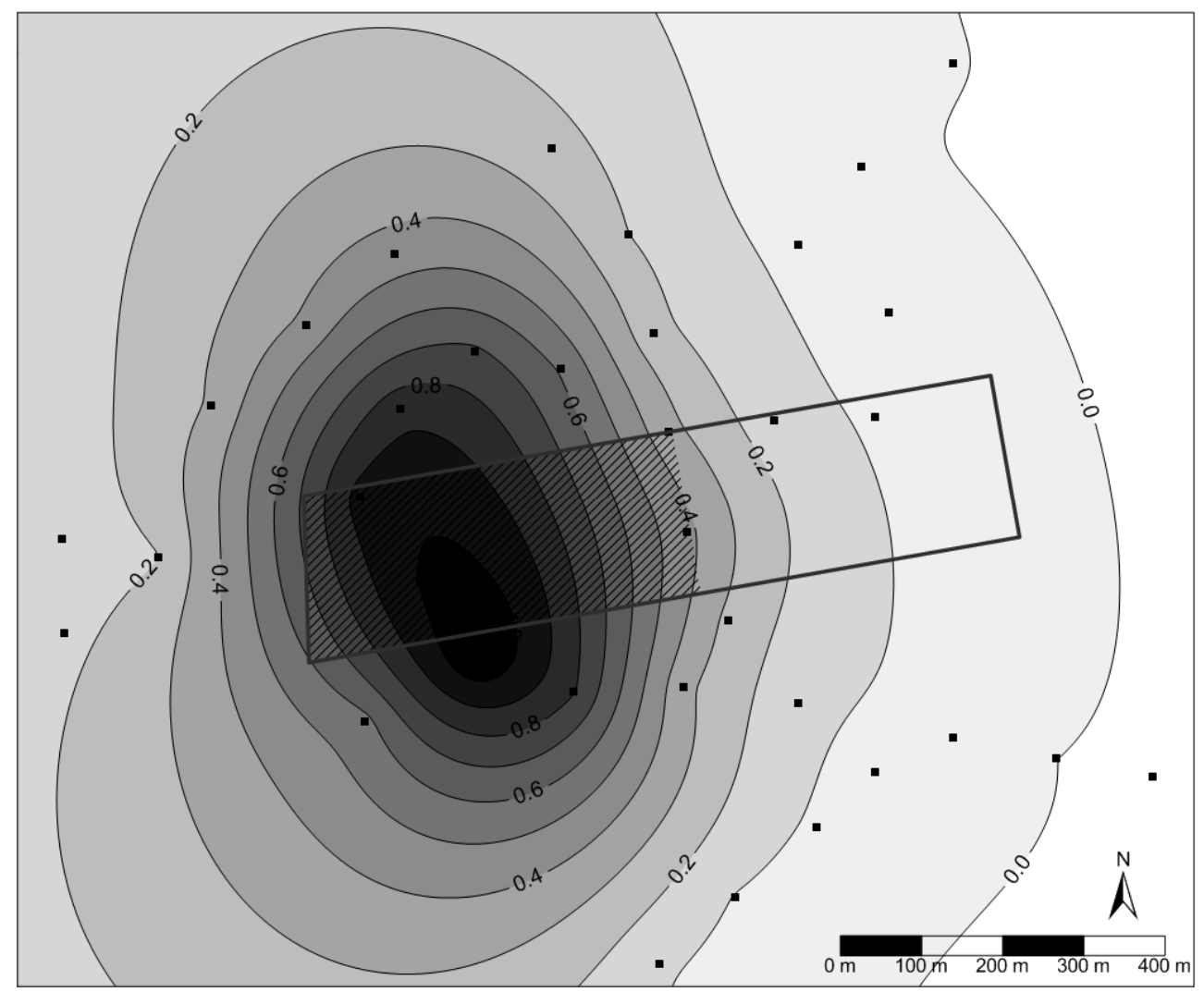

$2011 / 07-2012 / 03$

Subsidence $(\mathrm{m})$

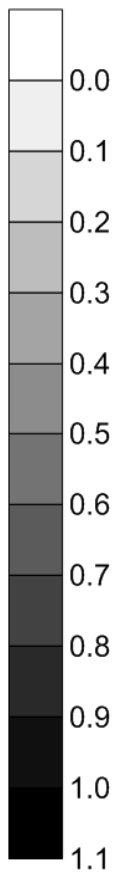

Fig. 3 Contour map of surface subsidence and mined out area of the 340206 mining panel before March $5^{\text {th }} 2012$.

east and with a drop size of $80 \mathrm{~m}$. East of the planned end of mining panel 340206 is the tectonic fault Eliška, inclined $70^{\circ}$ to the east and with a drop size of $50 \mathrm{~m}$. North of mining panel 340206 is the tectonic fault Ležatá, inclined $60^{\circ}$ to the North and reduced in the size to $30 \mathrm{~m}$.

Only the vertical component of the surface point motion, i.e. the subsidence, is taken into account in modelling the creation of the subsidence depression. The size of the surface point subsidence is determined as the difference between two elevations obtained from periodic surveying. If a network of surface points is used for surface height surveying, it is possible to model the creation of the subsidence depression.

In order to measure movements on the surface, points were fixed in a surface network the position and elevation of which is periodically surveyed by the Global Navigation Satellite System (GNSS; Doležalová et al., 2012; Kajzar et al., 2012). In this case, the geostatistical kriging interpolation method with a linear variogram model was used as a subsidence modelling method. The contour maps in Figures 2 and 3 show the progress of the subsidence depression until October $13^{\text {th }} 2011$ and March $5^{\text {th }}$ 2012, respectively. A contour map is a 2D representation of 3D data. The first two dimensions are the $\mathrm{x}$ and $\mathrm{y}$ coordinates and the third dimension is represented by isolines. The relative spacing of the contour lines indicates the relative slope of the surface subsidence.

The gate on the north side of mining panel 340206 was selected for monitoring the manifestations of longwall face advance at the adjacent mine gates. This gate was equipped with a series of three-level extensometers in the roof, and also with dynamometers, which monitor the process of loading selected anchor reinforcement elements. A special cone gauge probe was installed in the overburden of the selected gate at a chainage of $340 \mathrm{~m}$ to monitor stress-induced changes (see Figure 1). The mutual distance of both the perpendicular projections of the gauge probe and point d13 location on the gate directional line was $210 \mathrm{~m}$. An upward borehole with a length of $19 \mathrm{~m}$ and diameter of $76 \mathrm{~mm}$, with a special conical-shaped bottom, was used. Consequently, an oriented strain gauge measuring probe was glued into this modified borehole. Stress was detected using the CCBM probe (Compact Conicalended Borehole Monitoring), which is based on accurately measuring the deformations of the conical bottom of the borehole. Then, using laboratory tests which had determined the mechanical properties of materials from the probe's place of installation, these deformations could be transformed into the shape of the stress tensor (Sugawara and Obara, 1999). The values were collected at a frequency of about one week and were compared to the current position of the 

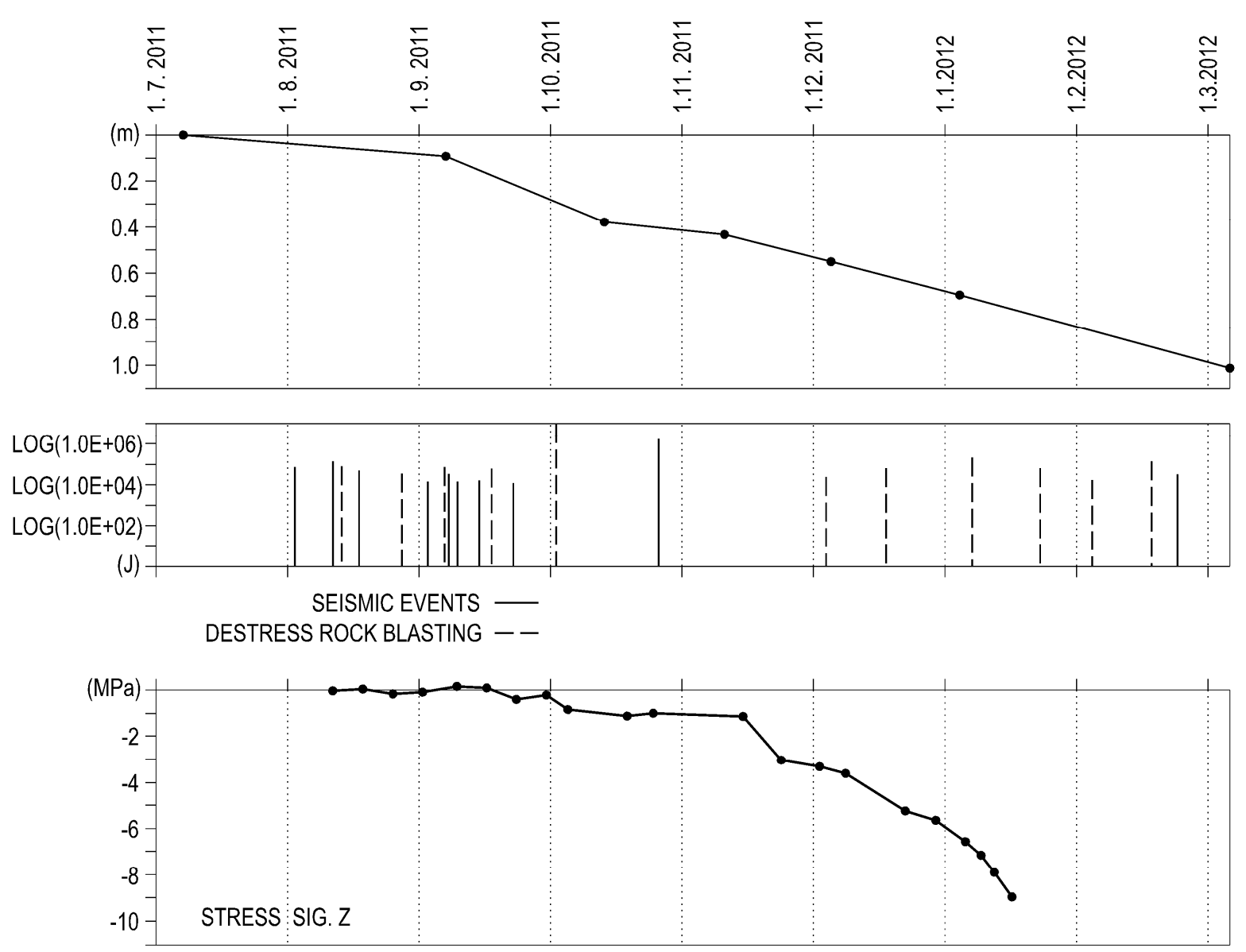

Fig. 4 Subsidence of surface point d13, with graphical display of registered significant SL events and stress changes in the vicinity of the goaf.

longwall face. Based on these measurements, dependencies of stress state changes were continuously constructed, i.e. the full shape was calculated of the tensor of the stress changes that were induced by the progress of the longwall face (similar to Staš et al., 2011). For the purposes of this article, the dependence of the change in the selected vertical stress component (negative values represent compression) in relation to the time axis is shown at the bottom of Figure 4.

\section{ASSESSMENT OF THE FAILURE OF OVERLYING STRATA}

It is necessary to consider the rigid overlaying strata as a stratified nonhomogeneous beam composed of layers that vary in thickness and firmness and which are faulted by a complicated system of tectonic faults. The uneven distribution of the mechanical properties of the overlaying rocks in the stratified mountains also results in their diverse deformations. The overburden is formed of rigid layers with a large bearing capacity, but with only a small capability of deflection. These layers are deformed in a brittle manner after exceeding the strength limit. The overburden is further formed of layers flexibly adapting to changing storage conditions and is capable of great deflection, and also of layers that can adapt to changed conditions in a plastic manner. This means that at the time of the rigid overlaying strata breakthrough, only those layers with a small deflection capability are deformed in a brittle manner. Deformation of flexible layers when a complete failure occurs is not fragile. A fragile failure of these layers occurs only subsequently as part of the mining progress (Jiránková, 2010; Jiránková, 2012).

Records of registered significant seismological (SL) events in the overburden are used when evaluating the failure of overlying strata. Seismic activity is continuously monitored in the OstravaKarvina region (OKR). Currently, seismic stations belonging to local and regional networks operate in the area. The local network is formed of stations managed by individual mines to monitor their own mining areas in the Karvina area of OKR. The regional network is formed of stations belonging to the Seismic Polygon of the Green Gas DPB, a.s. company. This Seismic Polygon contains ten stations. Data assessments by the local networks, together with 


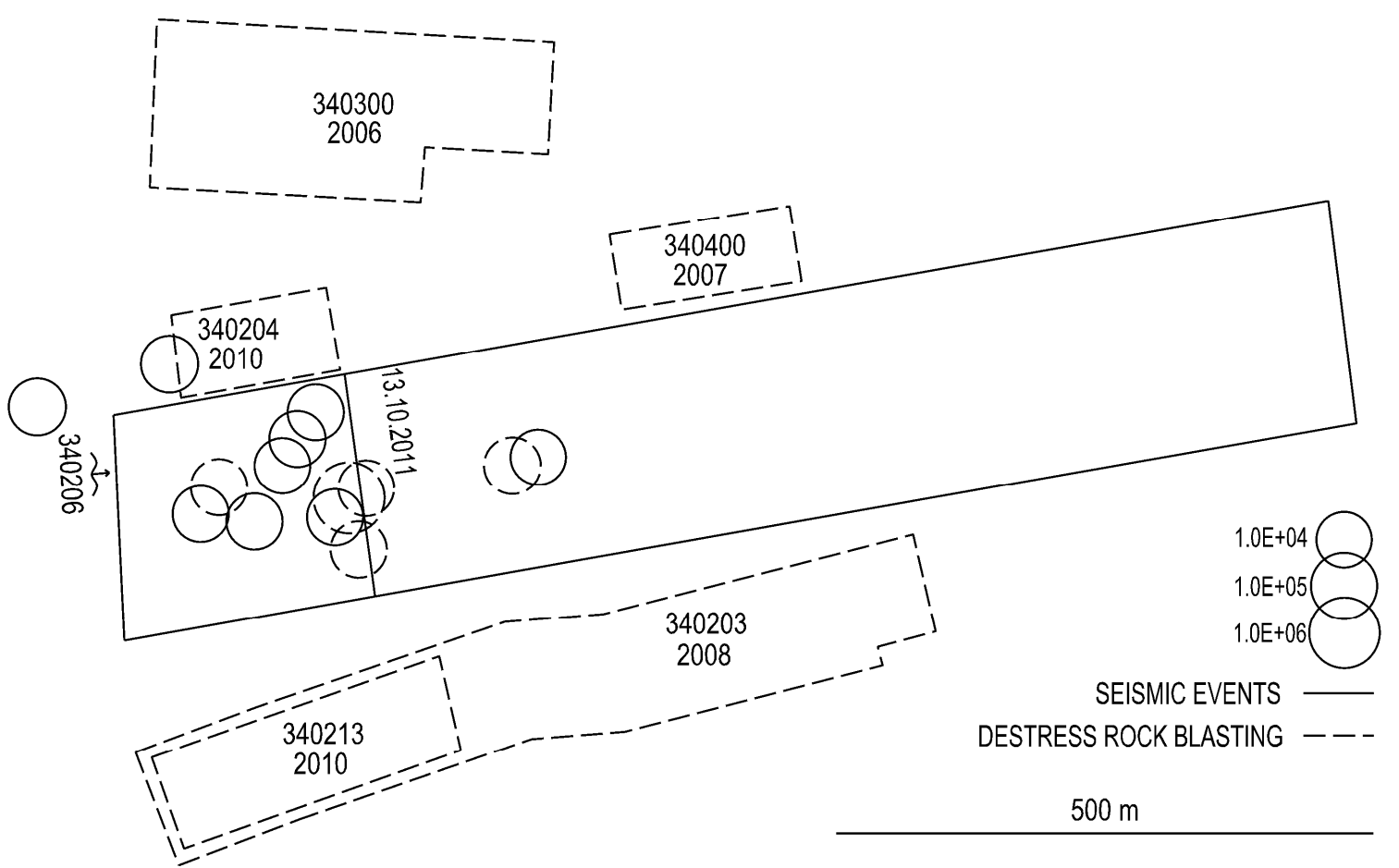

Fig. 5 Graphical display of significant SL events and advancing coalface before October $13^{\text {th }} 2011$.

those of the stations of the Seismic Polygon, have been processed since 2002 in the assessment centre at Green Gas DPB, a.s. in Paskov (Holečko, 2008).

Point d13 was selected to present a joint assessment of both surface subsidence and seismological activity during exploitation of mining panel 340206 (Figure 4). At the bottom of Figure 4 are graphically depicted measurements made of stress changes in the vicinity of the goaf. Registered SL events and the advance of the working face front until October 13th 2011 and until March 5th 2012 are graphically depicted in Figures 5 and 6 . The mutual distance of the projection of point $\mathrm{d} 13$ and the projection of the stress measurement point, which are both perpendicular to the directional line of gate 340226 , is about $210 \mathrm{~m}$.

Significant seismological events (with an energy greater than $10^{4} \mathrm{~J}$ ) are differentiated by whether they are of a natural character or whether they originate from destress rock blasting (DRB). The first significant SL event was registered 34 days after mining of the 340206 panel started. On that occasion, the working face front moved forward approximately $60 \mathrm{~m}$ in the direction of advance and the width of the working face was approximately $200 \mathrm{~m}$. Another SL event was registered nine days later. Both these registered significant SL events were natural and occurred North of the goaf. Then, a series of 11 events, both natural and caused by DRB, occurred between August $11^{\text {th }} 2011$ and September $22^{\text {nd }} 2011$. During this period, no significant stress changes were observed around the goaf (see Figure 4). At the same time, there was a gradual increase in subsidence of the surface points, and there was therefore a gradual failure of the overlying rocks. Natural SL events showed a brittle manner of deformation in some of the overlying strata. However, elastic deformation of the layers, which were flexibly adapting to the changing bedding conditions, were recorded in the layered overlying strata.

On October 10th 2011, DRB was undertaken with an extremely high seismic efficiency, which resulted in rockburst; the mine was so damaged that advance of the working face front had to cease for about five weeks. Subsequently, this resulted in a reduced increase in surface subsidence. During this break in mining, one significant SL event was registered (on October 26th 2011) in the area above the initial cross drift (see Figure 6). The stress change results (measured according to the methodology described in Staš et al., 2007, 2008, 2011, Knejzlík et al., 2008) made it apparent that the vertical component of the stress in the location of the installed probe reacted to DRB with an increase of the compression load, but barely changed when the longwall face advance stopped (Figure 4). A further gradual increase of the compression load in the vicinity of the goaf occurred only with the resumption of mining. The continuation of mining produced a new increase in surface subsidence and was accompanied by significant SL events that originated only from DRB. It can be assumed that at this time elastic 


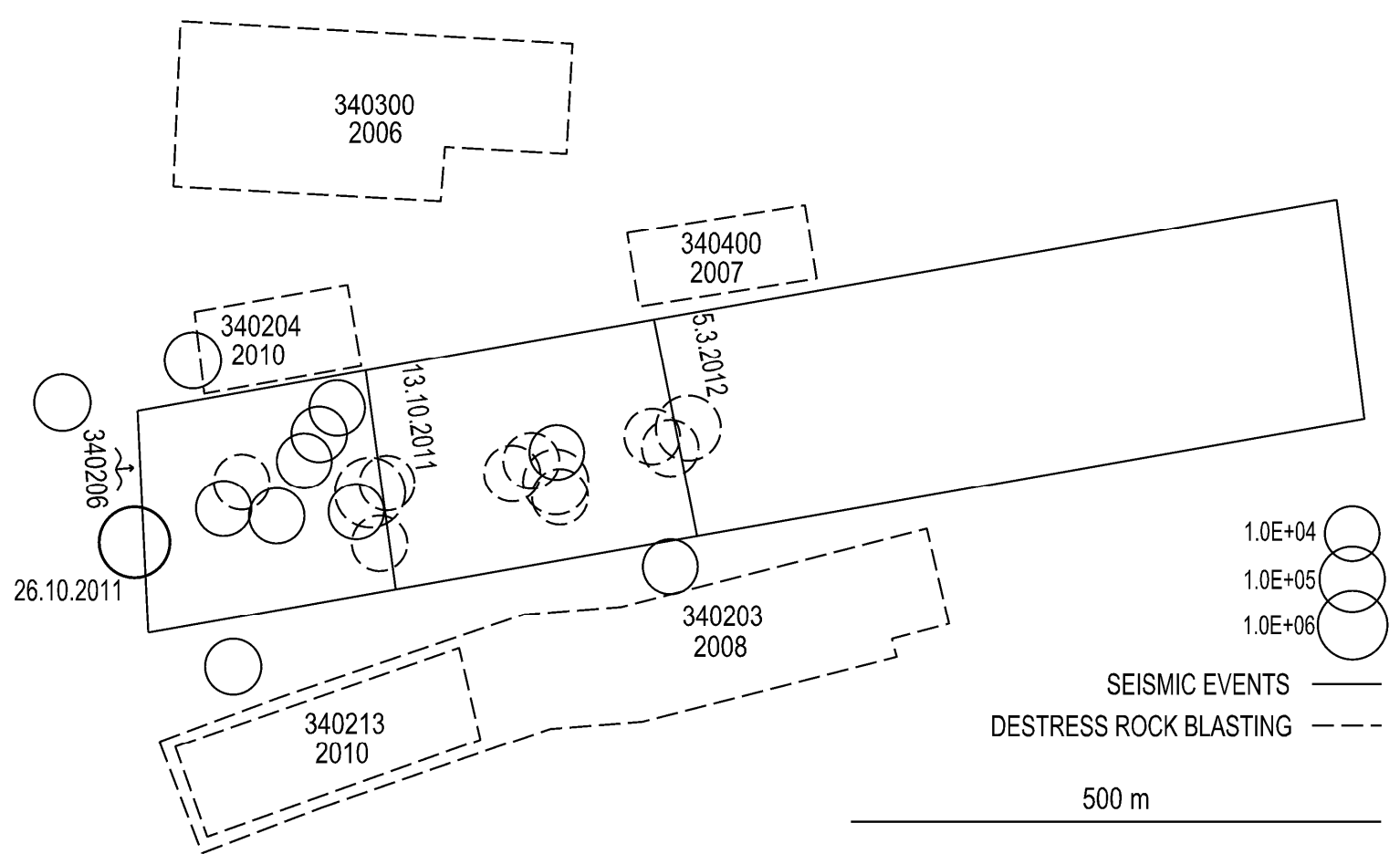

Fig. 6 Graphical display of significant SL events and advancing coalface before March $5^{\text {th }} 2012$.

deformations of the overlying strata were more dominant than brittle deformations.

The challenge is how to use the experiences of past evaluations from similar localities when the rock mass is highly inhomogeneous and the natural conditions are unique, not only in each area but also in each exploited mining panel. Therefore the assessment of failure of the overlying strata must be primarily based on measured data in the given area. Only then can the result of the assessment be of practical significance.

\section{CONCLUSION}

It is necessary to consider the rigid overlaying strata as a stratified non-homogeneous beam composed of layers varying in thickness and geomechanical conditions. The method of assessing failure of the strata failure overlying extracted coal seams is based upon the simultaneous assessment of surface subsidence and seismological activity, having regard to the spatio-temporal progress of mining and to the character of the rock mass. This means that at the time of breakthrough of the rigid overlaying strata, only those layers that have a small capability of deflection undergo brittle deformation. In contrast, the layers that have are better able to deflect flexibly can adapt to the changing bedding conditions at the time of failure of the rigid overlaying strata.

The development of the surface subsidence presented by the subsidence curve of point $\mathrm{d} 13$, together with records of registered significant seismological events and previous experience
(Jiránková et al., 2012), show that there was a gradual deformation of overlying strata during the extraction of mining panel 340206 . The apparent onset of surface subsidence is clear in Figure 2, accompanied by the occurrence of both natural seismological events and seismological events related to DRB (destress rock blasting). At this time (from August to October 2011), a gradual deformation of the rigid overlying strata occurred. After DRB was performed on October $10^{\text {th }} 2011$, the advance of the working face front ceased for about five weeks, which resulted in a reduced increase in surface subsidence. Additionally, it is apparent from the stress change measurement results that the vertical component of the stress in the location of the installed probe reacted to DRB with an increase of the compression load, but it hardly changed when the longwall face advance stopped.

The following mining activity brought a new increase in surface subsidence and was accompanied by significant seismological events that originated only from DRB. It can be assumed that at this time elastic deformations of the overlying strata dominated brittle deformations.

\section{ACKNOWLEDGEMENTS}

This paper has been prepared in connection with project ICT CZ.1.05/2.1.00/03.0082 (Institute of Clean Technologies for Mining and Utilization of Raw Materials for Energy Use), supported by the European Union and from the state budget of the Ministry of Education, Youth and Sports, and also in connection with the project VG20102014034. The 
aspects of safe performance of the underground mining openings at a depth over $800 \mathrm{~m}$ were supported by a grant from the state budget of the Ministry of the Interior of the Czech Republic.

\section{REFERENCES}

Doležalová, H., Kajzar, V., Souček, K. and Staš, L.: 2012, Analysis of surface movements from undermining in time, Acta Geodyn. Geomater., 9, No. 3 (167), 389400.

Holečko, J.: 2008, Refining the location of seismic events in OKR (in Czech). Proceedings of the 2nd Traditional Geomechanical and Geophysical Colloquium, Ostravice, $22^{\text {nd }}$ to $23^{\text {rd }}$ May 2008, 111-118.

Jiránková, E.: 2010, Assessment of rigid overlying strata failure in face mining, Central European Journal of Geosciences, 2, No. 4, 524-530.

DOI: $10.2478 / \mathrm{v} 10085-010-0014-7$

Jiránková, E.: 2012, Utilisation of surface subsidence measurements in assessing failures of rigid strata overlying extracted coal seams, International Journal of Rock Mechanics and Mining Sciences, 53, July 2012, 111-119. DOI: 10.1016/j.ijrmms.2012.05.007

Jiránková, E., Petroš, V. and Šancer, J.: 2012, The assessment of stress in an exploited rock mass based on the disturbance of the rigid overlying strata, International Journal of Rock Mechanics and Mining Sciences, 50, February 2012, 77-82. DOI: 10.1016/j.ijrmms.2012.01.004
Kajzar, V., Doležalová, H., Souček, K. and Staš, L.: 2012, Gabriela locality: starting geodetic observations to detect the surface manifestations from undermining, Acta Geodyn. Geomater., 9, No. 3 (168), 401-407.

Knejzlík, J., Rambouský, Z., Souček, K. and Staš, L.: 2008, Second generation of conical strain gauge probe for stress measurement in rock massif, Acta Geodyn. Geomater., 5, No. 3 (151), 257-265.

Staš, L., Knejzlík, J., Palla, L., Souček, K. and Waclawik, P.: 2011, Measurement of stress changes using compact conical-ended borehole monitoring, Geotechnical Testing Journal, 34, No. 6, 685-693.

Staš, L., Souček, K. and Knejzlík, J.: 2007, First results of conical borehole strain gauge probes applied to induced rock mass stress changes measurement, Acta Geodyn. Geomater., 4, No. 4 (148), 77-82.

Staš, L., Souček, K., Knejzlík, J., Waclawik, P. and Palla, L.: 2008, Measurement of stress change tensor by conical gauge probe, In: International Conference of IACMAG/12./. Bombay: Indian Institute of Technology Bombay, 1397-1404.

Sugawara, K. and Obara, Y.: 1999, Draft ISRM suggested method for in-situ stress measurement using the compact conical-ended borehole overcoring (CCBO) technique, International Journal of Rock Mechanics and Mining Sciences, No. 1, 905-912. 